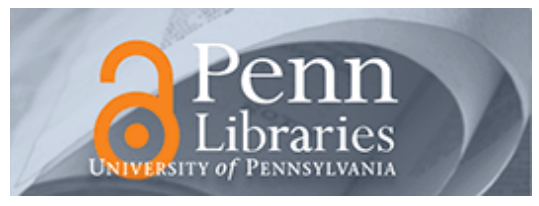

University of Pennsylvania

ScholarlyCommons

Marketing Papers

Wharton Faculty Research

3-2004

\title{
On the Depth and Dynamics of Online Search Behavior
}

Eric J. Johnson

Wendy W. Moe

Peter S. Fader

University of Pennsylvania

Steven Bellman

Gerald L. Lohse

Follow this and additional works at: https://repository.upenn.edu/marketing_papers

Part of the Behavioral Economics Commons, Business Administration, Management, and Operations Commons, Business Analytics Commons, E-Commerce Commons, Marketing Commons, Statistics and Probability Commons, and the Technology and Innovation Commons

\section{Recommended Citation}

Johnson, E. J., Moe, W. W., Fader, P. S., Bellman, S., \& Lohse, G. L. (2004). On the Depth and Dynamics of Online Search Behavior. Management Science, 50 (3), 299-308. http://dx.doi.org/10.1287/ mnsc. 1040.0194

This paper is posted at ScholarlyCommons. https://repository.upenn.edu/marketing_papers/274

For more information, please contact repository@pobox.upenn.edu. 


\title{
On the Depth and Dynamics of Online Search Behavior
}

\begin{abstract}
This paper examines search across competing e-commerce sites. By analyzing panel data from over 10,000 Internet households and three commodity-like products (books, compact discs (CDs), and air travel services), we show that the amount of online search is actually quite limited. On average, households visit only 1.2 book sites, $1.3 \mathrm{CD}$ sites, and 1.8 travel sites during a typical active month in each category. Using probabilistic models, we characterize search behavior at the individual level in terms of (1) depth of search, (2) dynamics of search, and (3) activity of search. We model an individual's tendency to search as a logarithmic process, finding that shoppers search across very few sites in a given shopping month. We extend the logarithmic model of search to allow for time-varying dynamics that may cause the consumer to evolve and, perhaps, learn to search over time. We find that for two of the three product categories studied, search propensity does not change from month to month. However, in the third product category we find mild evidence of time-varying dynamics, where search decreases over time from already low levels. Finally, we model the level of a household's shopping activity and integrate it into our model of search. The results suggest that more-active online shoppers tend also to search across more sites. This consumer characteristic largely drives the dynamics of search that can easily be mistaken as increases from experience at the individual level.
\end{abstract}

\section{Keywords}

electronic commerce, dynamic consumer search, stochastic models, consumer behavior

\section{Disciplines}

Behavioral Economics | Business | Business Administration, Management, and Operations | Business

Analytics | E-Commerce | Marketing | Statistics and Probability | Technology and Innovation 


\title{
On the Depth and Dynamics of Online Search Behavior ${ }^{1}$
}

\author{
July 2002 \\ Eric J. Johnson \\ Department of Marketing \\ Columbia Business School \\ Columbia University \\ Wendy W. Moe \\ Department of Marketing \\ McCombs School of Business \\ University of Texas at Austin \\ Peter S. Fader \\ Department of Marketing \\ The Wharton School \\ University of Pennsylvania \\ Steven Bellman \\ University of Western Australia \\ Gerald L. Lohse \\ Accenture
}

1 We thank Media Metrix, Inc., for providing the data used here, and the supporting firms of the Wharton Forum on Electronic Commerce for their financial support. Please do not quote or cite without permission. Correspondence should be directed to the first author, who can be contacted at ejj3@columbia.edu. 


\title{
On the Depth and Dynamics of Online Search Behavior
}

\author{
Abstract \\ This paper examines search across competing electronic commerce sites. By analyzing \\ panel data from over 10,000 Internet households and three commodity-like products (books, CDs \\ and air travel services), we show that the amount of online search is actually quite limited. On \\ average, households visit only 1.2 book sites, $1.3 \mathrm{CD}$ sites, and 1.8 travel sites during a typical \\ active month in each category. Using probabilistic models, we characterize search behavior at \\ the individual level in terms of (1) depth of search, (2) dynamics of search, and (3) activity of \\ search. \\ We model an individual's tendency to search as a logarithmic process, finding that shoppers \\ search across very few sites in a given shopping month. We extend the logarithmic model of \\ search to allow for any time-varying dynamics that may exist causing the consumer to evolve \\ and, perhaps, learn to search over time. We find that for two of the three product categories \\ studied, search propensity does not change from month-to-month. However, in the third product \\ category, we find mild evidence of time-varying dynamics, where search decreases over time \\ from already low levels. Finally, we model the level of a household's shopping activity and \\ integrate it into our model of search. The results suggest that more active online shoppers tend \\ also to search across more sites. This consumer characteristic largely drives the dynamics of \\ search that can easily be mistaken as increases from experience at the individual level.
}




\section{On the Depth and Dynamics of Online Search Behavior}

\section{Introduction}

Electronic commerce has engendered a widely held belief: that because the Internet lowers search costs, people should search more. There is little doubt that search costs, as measured by time, have decreased. Consider the contrast of shopping for a book offline versus online, knowing its title. Traveling from bookstore to bookstore, even in a shopping mall, might take minutes, but a typical search agent (such as DealTime) will search dozens of stores and provide prices, including shipping and sales tax, within seconds.

In accord with most economic models of search, many expect this increased search would lead to lower prices, as shoppers explore a larger number of vendors, reducing both the average price paid and the dispersion of prices (Smith et al. 2000). Most search theory (see Diamond 1987, for a review) concentrates on optimal strategies for search, usually in the form of a cutoff stopping price $\mathrm{p}^{*}$, which varies as a function of search cost.

If upon visiting a store one observes a price greater than $\mathrm{p}^{*}$, optimal behavior calls for further search, while prices below $\mathrm{p}^{*}$ calls for an end of search and purchase. Thus as $\mathrm{p}^{*}$ decreases, search increases. Furthermore, as search costs decrease, search itself increases and p* decreases. Similarly, an increase in the variance of the distribution of prices (holding constant the mean utility from a randomly selected price) makes search more valuable and lowers the cut-off price.

Bakos (1997) develops a model that includes the strategic responses of retailers and concludes that "consumers with access to electronic marketplaces, and thus facing lower search costs, become more demanding and are willing to make fewer compromises concerning their 
ideal product. If the cost of search is low enough, buyers look at all product offerings and purchase the one best serving their needs." His first model demonstrates that, in commodity markets, reductions of search costs may "destabilize a monopolistic equilibrium and eradicate sellers' profits." For differentiated goods, the picture is similar. Sellers' prices decrease smoothly as search costs are reduced. If search costs are low enough, buyers will search all vendors, thus finding products that are more closely matched to their needs and, when the number of vendors is large, reducing sellers' profits to zero. Most economic models of search have two separable predictions for the effect of reducing search cost upon prices: (1) a decrease in observed prices and (2) a decrease in the dispersion of prices (Smith, Bailey and Brynjolfsson, 2000).

These theoretical models beg the question: Does decreased search cost on the Internet really lead to lower prices? Researchers have sought to answer this question by comparing price levels on the Internet to those found in traditional "bricks-and-mortar" channels, focusing on products that are difficult to differentiate, such as books, compact disks, etc. Surprisingly, perhaps, the data are mixed. An initial study by Bailey (1998) examined prices for books, CDs and software and found that prices were actually higher on the Internet in 1996 and 1997 than in "bricks-and-mortar" stores. Brynjolfsson and Smith (2000), on the other hand, found that prices for CDs and books were 9 to 16 percent lower on the Internet. However, the differences observed between studies may be due to differences in the samples and methodologies used across the two studies.

Price dispersion presents a clearer picture of search cost effects. Both Bailey (1998) and Brynjolfsson and Smith (2000) find significant dispersion for CDs and books. Prices for identical items differed, on average, by 33\% for books and 25\% for CDs. Clay, Krishnan and Wolf (2001) found significant dispersion and differentiated retail strategies in the online book 
industry, with the largest retailer Amazon, presenting a price premium 10-25\% over the lowest cost provider. A study by Clemons, Hann, and Hitt (2002) of online travel agents again showed high levels of dispersion, even when they controlled statistically for the quality of the booked ticket, using the number of connections and the proximity of a flight to the requested time. The lowest and highest priced tickets varied, on average, by at least 10\% (or \$50) across online travel agents. An important exception to this pattern is provided by Brown and Goolsbee (2001) who argue that price dispersion first increases, then decreases, along with prices as a result of online comparisons for life insurance

These mixed results lead to another interesting question: How much do people really search online? One possible explanation for the existence of varying levels of price dispersion is that search itself varies. There is some evidence for limited search: Adamic and Huberman (1999) found that the top $1 \%$ of sites on the Web capture $50 \%$ of all visits to the Web, consistent with the idea that shoppers are limiting their search to a few popular sites. These ideas have an analogue in physical space as well. There is an extensive literature describing search for goods, mostly based on self reports (see Newman 1977 for a review). For example, the number of stores visited for the purchase of a major appliance is reported to be about three (Beatty and Smith 1987). Prior research has often argued that the observed amount of search is surprisingly low (Wilkie and Dickson 1985). However recent research suggests that consumers' priors may account for some of this departure (Moorthy et al. 1997). The current research allows us to revisit some of these issues both because of the decreased costs of search provided by the Internet and the use of observational data about search, which although imperfect may be superior to self reports that have been reported to be poor measures of actual search (Newman 1977). 
In this paper, we try to understand these issues by looking directly at search behavior of shoppers as they visit online retailers. It is our hope that this analysis is descriptively interesting and can help explain some of the observed patterns of prices that have puzzled observers of online markets (Smith et al. 2000). Because electronic markets often allow us to observe search (whereas data from offline markets are generally restricted to purchasing transactions only), we think this is both an important new source of evidence, and perhaps an "early warning system" for increases in price competition. In addition, we can examine how the depth of search systematically differs across consumers and can therefore offer models that will allow us to separate the factors that might influence search.

Given available data, we face several challenges. Our major data will be site visiting behavior and the tendency for shoppers to visit multiple sites. Because buyers frequently shop multiple channels and because clickstream data does not identify purchases, it is difficult if not impossible to definitively link store visits to a specific purchasing decision. Our strategy then is to examine search across a variety of sites within a specified window of time as a close approximation. Though this behavior may represent shoppers' overall tendency to search for information and not necessarily their tendency to price search, it does serve as an upper bound. We find that overall, this behavior (i.e., search for information) is low, much lower than expected. Because price search is a subset of information search, our results will overestimate, to some degree, the amount of price search.

\section{Data}

We examine consumer search directly, by looking at the shopping patterns of a large panel of Internet users over time. We use data collected by Media Metrix, Inc., a firm that 
records every URL visited by families that are members of its panel using a small program, the PCMeter, which runs continuously as a background application on the family's home computer. The U.S. panel we analyzed corresponded to approximately 10,000 households at any given point in time, recruited by Media Metrix to be representative of the U.S. population. We examine the online shopping behavior of each of these households during the 12-month period from July 1997 through June $1998^{2}$. Specifically, we are interested in the number of unique sites searched by each household within a given product category. A key issue when examining search behavior is defining the period of time that constitutes a search session. For example, the industry practice is to define a user session by "closing" the session after 15 minutes of inactivity. However, that is a fairly narrow definition of a search session as it is conceivable that a shopper's decision period, and therefore search, may span over multiple days, weeks, etc. In fact, search on the Internet can be better characterized as a series store visits over a span of days which "build-up" to a purchase (Moe and Fader 2002). Conceptually, these shoppers are accumulating information toward a purchasing threshold before the final purchasing decision is made, perhaps days later, during an entirely different store visit. While similar behavior has been documented offline (Putsis and Srinivasan 1994), this behavior is much more common in the online environment due to the lower costs of "traveling" to the store. One may visit a given site today to examine the product offering, then deliberate the purchase offline, and return to shopping online days later.

An alternative method of defining a search session is to close the session after a purchase is made and assume that all store visits prior to that purchase contributed to that purchase cycle. There are three problems with this method as well. First, not all purchases are made online. A 
shopper may search online and make some purchases offline. In that case, search sessions as defined strictly by observed online purchases might in fact include multiple purchase cycles. Second, clickstream data typically includes only the URLs viewed and does not necessarily offer any insight into purchasing activity. While some sites, such as Amazon and CDNOW, may have easily identifiable URLs that indicate a purchase occurred, many sites do not offer any such indication. Third, after a shopper views the product selection at one or more sites, he/she may simply decide not to buy at all for whatever reason, and the next visit may be related to a completely unrelated purchasing decision. In these instances, store visits cannot be linked to any specific future visit that contains a purchasing transaction.

Our objective is to define a session broadly enough to encompass a series of site visits that contribute to the same purchasing cycle but also narrowly enough not to inadvertently merge multiple cycles. As a result, we chose to examine each household's search behavior at the monthly level, which allows us to avoid making any assumptions (or incorrect inferences) about the link between purchasing and online visit behavior. ${ }^{3}$

We focused on three categories: compact discs, books, and air travel, choosing them because: (1) they were relatively frequently purchased online during this time period; (2) they tend to be non-differentiated goods (a book purchased from Amazon is the same book purchased from a low cost provider such as Books.com), increasing the probability that these categories will be subject to broader search; (3) they vary in price from relatively inexpensive (books and CD's) to more expensive (air travel); and (4) they have been used in studies of price and price

\footnotetext{
${ }^{2}$ We used the information contained in the URL of the site to determine the product category. The end of this time period corresponds to the entry of one of the on-line stores, Amazon, into multiple categories, making determination of the product class ambiguous.
} 
dispersion by other researchers. Sites were chosen from each category according to lists of leading online retailers from Media Metrix, BizRate (http://www.bizrate.com) and Netscape's "What's Related" feature, which uses Alexa's records of consumers' actual surfing behavior to identify related sites. While there may be some sites that are excluded from the analysis, they would probably constitute a very small fraction of the activity in each category. Specifically, our dataset covers consumer search activity across 13 book sites, 16 music sites, and 22 travel sites (Table 1), a more inclusive set of sites within each category than that used by either Brynjolfsson and Smith (2000) or Clemons et al (2002). Sites included in each category range considerably in terms of visitor traffic (Table 1 also provides the number of searches experienced by each site). For example, the smallest CD site in our dataset attracted only 11 unique visitors from the Media Metrix panel while the largest in the same category attracted over 1800 unique visitors.

\section{Analysis, Models, and Results}

Using these data, we first examine the number of stores visited in a typical month. Figure 1 shows the average number of websites visited by households each month in which they were actively shopping in the product category. For example, the average number of CD sites searched in a household's first month of shopping is 1.23 and increases to 1.62 in the fourth

\footnotetext{
${ }^{3}$ We examined the number of these month-long sessions that contained more than one purchasing transaction to confirm that our definition for "session" was not so long as to include multiple purchasing cycles. Since our data only contained purchasing information for a limited number of retailers, we obtained this information for the most popular site in each category for which we had purchasing information. The results revealed that in each case, fewer than $1 \%$ of all month-long sessions contained more than one purchasing transaction.
} 
shopping month for those households that shopped in four (or more) different months in the dataset.

Insert Figure 1 about here

Two patterns are striking in the data. First, the overall level of search is low, initially ranging from 1.1 stores for books to 1.8 for travel. In fact, $70 \%$ of the $\mathrm{CD}$ shoppers, $70 \%$ of the book shoppers, and $42 \%$ of the travel shoppers were observed as being loyal to just one site throughout the duration of our data. Second, there seems to be an increase in search from month to month. This seems to suggest that Internet search, while currently fairly low, may be increasing over time. One possible explanation for the increasing trend seen in Figure 1 is that consumers may be evolving and searching more as they gain experience, consistent with the idea that time will lead to lower prices and reduced dispersion. We will more closely examine this dynamic of search in the next section.

However, aggregate patterns like those in Figure 1 can be misleading, since they can, in principle, mask different underlying trends that may exist at the individual level. To model these trends, and to provide a more accurate portrait of shopping behavior, we examine search using a model that allow us to decompose this data into three components: (1) Depth of search: the decision of the household to visit more than one store in a given month, (2) Dynamics of search: the evolution of the number of stores visited over time, and (3) Activity of search: the overall amount of category-level shopping activity for each household in a given product class. 


\subsection{Depth of Search}

Consumer search has been theoretically modeled as a process in which the consumer's decision to seek out additional information is a function of the expected benefit of that added information (Diamond 1987). As a consumer obtains more information from visiting additional store sites, the expected benefit provided by seeking out new information decreases. As a result, the probability of soliciting information from an additional source is likely to decrease. To capture this process, we model the probability that individual $i$ searches an $x^{\text {th }}$ site as a decrement of the probability of visiting the $\left(x_{i}-1\right)^{\mathrm{st}}$ site:

$$
\operatorname{Pr}\left[X_{i}=x_{i}\right]=\frac{\left(x_{i}-1\right) \theta_{i}}{x_{i}} \operatorname{Pr}\left[X_{i}=x_{i}-1\right], \quad x_{i}=2,3, \ldots,
$$

where $\theta_{i}$ is an individual-specific search propensity parameter $\left(0<\theta_{i}<1\right)$. Lower values of this parameter indicate an increasing likelihood of stopping with a small search set, but even at its maximum value $\left(\theta_{i} \rightarrow 1\right)$, the probability of searching an additional site will always be a decreasing function of $x_{i}$.

The model presented in equation (1) is well-suited for the type of search behavior described above. Working backwards through this recursive relationship, we can obtain the logarithmic distribution (Johnson et al. 1993).

$$
\operatorname{Pr}\left[X_{i}=x_{i}\right]=\frac{a_{i} \theta_{i}^{x_{i}}}{x_{i}} \quad x_{i}=1,2, \ldots
$$

where $a_{i}=-\left[\ln \left(1-\theta_{i}\right)\right]^{-1}$ and $0<\theta_{i}<1$. To illustrate the process, Figure 2 plots the shape of the logarithmic distribution for a variety of $\theta$ 's. 


\subsection{Dynamics of Search}

The logarithmic distribution given in equations (1) and (2) models the number of sites searched by an individual in a given session. However, in our data, we observe each individual across multiple search sessions. This will allow us to more closely examine potential dynamics that may exist in search propensity as shoppers gain more experience in a particular category.

Recall that the data show that search propensity is surprisingly low given the ease of visiting multiple stores online. One explanation is that people are still learning to search, and over time, as consumers familiarize themselves with the Internet environment, search propensity will increase. This argument would be consistent with the apparent trends seen in Figure 1. We explicitly test this argument by including a model component that captures and measures the change in search propensity from session to session.

Specifically, we allow the search propensity parameter, $\theta_{i}$ to vary from visit to visit for each panelist. In other words, the probability that individual $i$ will visit $x_{i j}$ sites in the $j^{\text {th }}$ month is a function of a search propensity parameter, $\theta_{i j}$.

$$
\operatorname{Pr}\left[X_{i j}=x_{i j}\right]=\frac{a_{i j} \theta_{i j}{ }^{x_{i j}}}{x_{i j}} \quad x_{i j}=1,2, \ldots,
$$

Because $\theta_{i j}$ is constrained to be between zero and one, we apply a logistic transformation $\theta_{i j}=$ $\exp \left\{\theta_{i j}^{*}\right\} /\left[1+\exp \left\{\theta_{i j}^{*}\right\}\right]$ and assume that $\theta_{i j} * \sim \mathrm{N}\left(\mu_{\mathrm{j}}, \phi\right)$. We operationalize changes in individual search propensity over time through the mean of the $\theta_{i j}{ }^{*}$ distribution:

$$
\mu_{\mathrm{j}}=\beta_{0}+\beta_{1} \ln (j)
$$

The parameter $\beta_{0}$ represents the baseline propensity to search while the parameter $\beta_{1}$ indicates how search propensity changes as a function of experience. If $\beta_{1}$ is positive, then search increases with experience. However, if $\beta_{1}$ is negative, then search decreases as a function of 
experience. To accommodate heterogeneity, we assume that $\beta_{0}$ and $\beta_{1}$ are normally distributed with mean and standard deviation to be estimated.

\subsection{Activity of Search}

An alternative explanation can also generate the patterns shown in Figure 1 and offers a very different interpretation of these data. Specifically, the pattern that we observe in Figure 1 could stem from a selection effect. Because we are able to observe more activity from the frequent shoppers in our dataset, we observe an increasingly greater proportion of these more active households as we move from left to right in the figure. These relatively active shoppers (i.e., those who visit a particular category more frequently) may be inherently different from those less active and may tend to search across more sites. As a result, the increase we see may not represent more stores being visited over time by a typical panelist, but rather a change in the mix of shoppers as we move to a greater number of active months. Simply put, heavier users may be represented more in later months. There may be no household-level dynamics whatsoever, but only an apparent pattern resulting from heterogeneity alone.

To explore the relationship between the level of shopping activity levels and depth of search, we extend equation (4) to include a second individual-specific covariate - a measure of category-level search activity, $q_{i}$ :

$$
\mu_{i j}=\beta_{0}+\beta_{1} \ln (j)+\beta_{2} \ln \left(q_{i}\right)
$$

Again, the coefficient $\beta_{2}$ is assumed to be normally distributed with mean and variance to be estimated.

One measure we could use to characterize a household's activity level is the proportion of months for which the household was actively shopping. However, there is a critical drawback of using such a measure - not all households are present in the panel for equal amounts of time. 
For example, a household that was in the panel for only a month and was also active in that month would be represented by this measure as being active $100 \%$ of the time (or every month) even if this individual's true activity level is significantly less frequent (e.g., every 6 months). However, because we are only able to observe a small sample of each shopper's lifetime behavior, any measure based on this limited history is likely to misrepresent that individual's latent and true tendencies in behavior. Therefore, instead of directly measuring shopping activity from the data, a better measure would incorporate a Bayesian shrinkage estimate that allows for some regression to the mean, derived from a separate category-level model of activity ${ }^{4}$.

We examine the number of months each individual is actively shopping as a zerotruncated binomial process (since only those who have conducted at least one search are included in our dataset). Each individual household in the panel has a probability, $q_{i}$, of visiting a product category in any given month they are in the panel (regardless of which store(s) they choose to visit). Given that household $i$ was in our dataset (but not necessarily active in a given category) for $T_{i}$ months, the probability of shopping in $J_{i}$ of those $T_{i}$ months is:

$$
P_{i}\left(J_{i} \mid T_{i}, q_{i}\right)=\frac{\left(\begin{array}{c}
T_{i} \\
J_{i}
\end{array}\right) q_{i}^{J_{i}}\left(1-q_{i}\right)^{T_{i}-J_{i}}}{1-\left(1-q_{i}\right)^{T_{i}}}
$$

Furthermore, we assume $q_{i}$ to be distributed across the population according to a beta distribution with parameters $k$ and $m$ to allow for heterogeneity in these activity levels. This mixture model will provide for us a general measure and method of assessing each individual's shopping activity. We use the expectation of $q_{i}$ conditional on each individual's observed behavior. This completes the description of our complete model specification.

\footnotetext{
${ }^{4}$ We estimated the search depth models using both a Bayesian estimate of search activity $\left(q_{i}\right)$ as a covariate as well as using a direct measure of search activity (\# of months active / \# of months in panel) for each of the three
} 
We estimate this hierarchical Bayesian model using a freely available software package, winBUGS, which uses Markov chain Monte Carlo methods to obtain a distribution for each model parameter. We followed standard practice by simulating 10,000 iterations of the model, discarding the first 5,000 as an initial burn-in. Appropriate and diffuse priors and hyperpriors were specified. Specifically, the hyperpriors in the search depth model were specified as:

$$
\mu_{\beta} \sim \operatorname{normal}(0,10) \text { and } \sigma_{\beta} \sim \operatorname{gamma}(10,10)
$$

The priors in the search activity model were specified as:

$$
k \sim \operatorname{gamma}(10,10) \text { and } m \sim \operatorname{gamma}(10,10)
$$

We also estimated a model that allowed for correlation between depth of search and activity of search. We did this by specifying the coefficients in equation (5) and the parameters of the activity model in equation (6) as coming from a multivariate normal distribution with a correlated error structure:

$$
\left[\begin{array}{c}
\boldsymbol{\beta}_{0 i} \\
\boldsymbol{\beta}_{1 i} \\
\boldsymbol{\beta}_{2 i} \\
q_{i}
\end{array}\right] \sim M V N(\boldsymbol{\mu}, \boldsymbol{\Sigma})
$$

In two of the three product categories we tested (books and music), the correlation between search activity, $q_{i}$, and the baseline propensity to search, $\beta_{0}$, was not significantly different from zero. In the air travel category, the mean correlation was significant; however, the overall fit of the correlated model was poorer in comparison to the uncorrelated model in terms of the Bayesian information criterion (198,386 vs. 197,980). Therefore, for the remainder of the paper, we will discuss the results from the uncorrelated model with the depth of search

product categories. We found that, in each case, the model using the Bayesian estimate of search activity fits significantly better than the model with a direct measure of activity. 
component specified by equation (5) and the activity of search component specified by equation (6).

\subsection{Results}

The resulting parameter estimated are presented in Table 2 along with the $90 \%$ and $95 \%$ confidence bounds calculated from the MCMC simulations. For all three product categories, more active households seem to search more store sites than the less active households (i.e., $\beta_{2}$ is significantly positive). However, evidence of any month-to-month dynamics at the household level, is limited. We first address the issue of time dynamics before discussing the relationship between search depth and search activity.

Insert Table 2 about here

For two of the three product categories we examined (books and music), we find no significant effect of time dynamics, $\beta_{1}$, on propensity to search $(p>0.10)$. For air travel, however, we do find significant, but negative, time dynamics $\left(E\left[\beta_{1}\right]=-0.167\right)$. In other words, as we observe subsequent shopping sessions for an individual, the mean propensity to search actually declines. This is contrary to arguments suggesting that consumers are still learning how to search online and the currently low levels of search will increase as they gain experience and search becomes less difficult. Instead, our results indicate that the effect on search propensity from increased consumer experience is reversed. We find that the level of search being conducted now, however low it may be, is only decreasing as consumers gain experience in that 
product category (as indicated by $\beta_{1}<0$ ). Rather than learning how to search, consumers seem to be gravitating toward a preferred site over time, at least in the case of air travel.

In contrast, the effect of category-level search activity, $\beta_{2}$, is significant and positive across all three product categories $(p<0.05)$. This strongly suggests that the downward trend seen in Figure 1 is the result of a selection effect where the more frequent searchers tend to search more sites in any given active month. Figure 3 plots the relationship between search activity and the depth of search. In the upper part of the figure, the solid line indicates the median expected number of sites searched at each activity level, $q$, and the dotted lines indicate the $90 \%$ confidence bounds. The lower portion of the figure is a histogram representing the distribution of panelists based on their category-level search activity. Overall, we see very low levels of search that increase for more active shoppers, but these more active shoppers are less abundant in the sample. Taken together, the two portions of Figure 3 demonstrate how the selection effects arise from the raw data.

In general, there seems to be very little search in the book and CD categories. The travel category reflects a bit more search but still far less than one might expect. The fact that search in the travel category is actually more than the amount of search seen in the books or CD categories may seem logical given that the size of purchase is large, and prices are dynamic. But on the other hand, since many travel sites feature comparison shopping tools within the site itself, it may seem a bit surprising that individuals search more across travel sites than they do in the books and $\mathrm{CD}$ categories. These latter categories consist of sites that are pure e-commerce vendors and not search 'bots. This observation provides an initial indication that search "bots are not the reason behind the limited search that we find in these categories; we discuss this issue in more detail later in the paper. 


\section{Discussion}

\subsection{Summary and Implications for Research}

In summary, these three categories show fairly low levels of search overall. While more active shoppers tend to visit more sites in any given month, there is no evidence that experience increases the number of sites visited. We might expect the greatest returns to search for travel services, both because prices can change over time and because this is a more expensive purchase. However, we find that experience leads to a slight decrease in the number of visited sites.

Our results suggest that people visit few stores online despite the fact that consumers are "just a mouse click away" from other stores. Browsing behavior varied by product category and level of activity but showed no increase with experience.

These findings may provide an important explanatory mechanism for Internet researchers who have been puzzled by the existence of substantial price dispersion. In understanding our results, it is important to realize that we examined product classes and time periods that are very similar to those used by researchers who have examined changes in price and price dispersion on the Web. The attraction of books, compact disks, and travel for examining these questions is their apparent commodity-like status, which should provoke higher levels of search. And our data have been collected during time frames that substantially overlap the periods used in prior studies of prices for CD's and books (Brynjolfsson and Smith 2000) and airline travel (Clemons et al. 2002). This minimizes the potential for historical differences and suggests that the lack of search is consistent with the observed price dispersion. The methods we develop here may be useful in future work that attempts to connect search with pricing in a more direct manner, if/when appropriate data become available. 
Our results have implications concerning the use of self-reports of search, because they stand in such sharp contrast to survey-based measures of online search. Self-reported data are subject to the fallibility of people's memories, idiosyncratic scale use, and even deliberate alteration through social desirability biases and have been found to have very little correlation with actual search. Industry analysis based on self-report suggests higher levels of search than we observe (e.g., a reported 2.4 visits per purchase noted by McQuivey 1999). We believe additional research is needed to compare self-reported behavior to actual Web usage, but the type of panel data examined here reflects actual behavior, and should serve as the appropriate baseline for such efforts. It is interesting to note that the one reported example of decreases in prices and dispersion (Brown and Goolsbee 2001) employs self-reports based on Forrester's research. Brown and Goolsbee suggest that recent declines in life insurance prices are the result of increased use of Internet shopping sites for insurance. An interesting next step would be to examine actual (as opposed to self-reported) usage data to see if observed search is correlated with lower prices paid. Similarly, it would be interesting to examine if observed search helps explain which shoppers will be most helped by buying online (Scott Morton et al. 2002)

\subsection{Caveats and Limitations}

\subsubsection{Data}

In this study, the analysis of depth of search and activity level of search was conducted at the household level, rather than at the level of the individual consumer. By aggregating consumers to the household level, we overstate both the activity level and depth of search. Households with multiple members shopping in different months would have an activity level that is higher than that of any one individual in the household. Similarly, households with 
multiple members who are each loyal to a different site will demonstrate greater search propensities at the aggregate household levels. Therefore, even though we observe low levels of search at the household level, search at the individual consumer level would be even lower.

A potential disadvantage of the type of clickstream data used here is that we identify all browsing activities, not just search behavior associated with purchases. While such browsing may be an important part of consumer search, we are unable to partition our observations into those associated with purchase-oriented behavior and those that may be associated with other activities (e.g., using Amazon.com to find biographical information about a certain author). While this may generally lead to an overestimation of the amount of search in our dataset, it is possible that purchase-related browsing might feature more extensive search than other "look up" activities.

Finally, the time period studied in this paper represents a fairly early stage in electronic commerce. As such, the subset of the consumer population shopping online may be very different from the consumer population as a whole. Studies conducted around the same period of time have found that online consumers tend to be more time constrained than the average consumer (Bellman et al. 1999). As such, this subset of the consumer population that shops online may consist largely of those consumers who are unable to spare the time to search across multiple sites. Projecting the search behavior of this subset of shoppers to the consumer population as a whole may lead to biased conclusions.

\subsubsection{The role of shopbots}

While the dataset used here contains a rich and realistic portrayal of online shopping, it is an early snapshot of such behavior. While it could be argued that the low levels of search documented here will change as the online market matures, our analysis of time-dynamics does 
not suggest this was happening in the time frame observed. All three classes showed no increase in the number of sited visited. One major trend which may well modify these results is the widespread adoption of price search agents, or price robots, termed 'bots for short. We examined our data for the use of such 'bots, but found that their use at this time was at very low levels. For example, the most popular was Acses, a price search agent for books (which later evolved into today's DealTime), which had a total of 17 uses in the Media Metrix panel. As consumers may become more sophisticated in their search over time and as search agent technology evolves, we may see automated search further lowering search costs and minimizing prices and price dispersion. However recent research indicates that even those who use shopping robots seem to display loyalty to sites previously used. Brynjolfsson and Smith (2001) examined users of EvenBetter.com, a popular search engine for books (also an early version of DealTime). It is interesting to note that even though this subset of Internet consumers were highly price sensitive and tended to patronize those stores with cheaper prices, over $51 \%$ of these customers did not choose the retailer with the cheapest price. Even with this self-selected group of consumers, the retailer brand had a significant advantage. Amazon, for example, commanded a price premium of $\$ 1.85$ over unbranded retailers according to their model.

\subsection{Why is search so limited?}

One possible explanation for why we see so little search is that the current market for these goods is efficient. However, the fact that there is still significant price dispersion in these Internet markets suggests that this is not the case. Brynjolfsson and Smith (2000) show significant price dispersion on the Internet and examine a number of possible explanations. One is that the product offerings may actually be heterogeneous and not commodities because of value-added services of various kinds. We dismiss this critique by examining the offerings of 
online book and CD vendors and argue that the offers do not differ significantly, and more importantly, do not differ as a function of price. Similarly, Clemons et al (2002) find that dispersion exists even when they control statistically for the quality of the airline tickets in their study. Thus, the dispersion found in these studies suggests that these markets have not yet produced the kind of highly efficient markets thought to be a natural hallmark of electronic commerce.

Another possibility is that normative models of search are not complete. While clearly any modifications of standard search models exceed the scope of this paper, it is worth noting that the heart of most search models is the tradeoff between the cost of search, usually measured by time, and the benefit of that search to the consumer. Other domains involving the allocation of time have benefited from richer descriptive frameworks incorporating the effects of context and mental accounts. Two examples that seem relevant are descriptive theories of time-money tradeoffs (Loewenstein and Prelec 1992; Loewenstein and Thaler 1997) and the observation that out-of-pocket costs are over-weighted relative to opportunity costs (Thaler 1999).

A third possibility is the realization that search costs are not constant over time and that they change as consumers gain experience shopping with a particular online store. For example, by visiting a site, one learns its navigational scheme, which reduces the cost of using that site in the future. Similarly, the site can make changes, through customization, user-based recommendations, and memorization of names, addresses and payment details that lower the cost of that site relative to others. This idea that search costs are dynamic is analogous to the concept of lock-in, which has been discussed in markets for technology goods, and is a topic we are exploring elsewhere (Johnson et al. 2002) 


\subsection{Managerial Implications}

From a managerial perspective, this paper suggests that, despite claims to the contrary, the Internet does not produce enormous amounts of search, even for products that are difficult to differentiate. However, this conclusion, while a fair characterization of the aggregate pattern of search, does depend upon the amount of category-level activity: more active households search more. From the perspective of the firm, these results can inform market selection, and help identify customer segments and tactics: infrequent customers who tend to search less may not need as much in the way of incentives for loyalty. At the same time, the most active, and perhaps valuable, customers are those most likely to shop around.

This research also reinforces the value of looking at individual, as opposed to aggregate data: the aggregate pattern, as portrayed in Figure 1, seems to support an explanation due to dynamic growth. However, careful modeling of the household-level data indicates that this is not occurring, and that the pattern results from differential activity. In fact for one product class, air travel, we actually see a slight decrease in search over time.

The bottom portion of Figure 3 makes this quite clear in terms of potential marketing segmentation and strategy: the very active shoppers are few in numbers in all categories, and shopping around seems limited to a few high activity (high $Q$ ) shoppers. At the same time, these may be customers of high value, so paying attention to their shopping habits, and developing tools to increase their loyalty may be prudent.

Beyond the specifics of these results, the methodology we introduced can serve as a continuing tool for e-tailers interested in the dynamic development of their customer base. Thus we think that a tracking study, producing a time-varying equivalent of Figure 3, would help managers identify changes in shopping activity and loyalty. In addition to this type of longitudinal extension to our work, it might also be worthwhile to profile households by looking 
at their search behavior across multiple categories. This might help managers anticipate and identify the kinds of behavioral patterns described above.

\subsection{Conclusion}

We see this research as in initial demonstration that data from the Web are changing our view of search from an unobservable explanatory variable in the analysis of markets to one that can and should be observed and included in empirical analyses of market behavior. The kind of analysis we do here cannot easily be done in off-line environments, and the kind of data used here can track search at a fine level. Much of the challenge in the evolving analysis of clickstream data will be to develop efficient methods for theory testing, given the large amount of data provided by shoppers on the Internet. While these challenges are significant, we believe the analysis of search data will be extraordinarily useful in expanding our understanding of the role of search in explaining marketplace behavior, and the analysis offered here represents a first step. 


\section{References}

Adamic, Lada A. and Bernardo A. Huberman (1999), "The Nature of Markets on the World Wide Web." Palo Alto, CA: Xerox Palo Alto Research Center.

Bailey, Joseph (1998), "Electronic Commerce: Prices and Consumer Issues for Three Products: Books, Compact Discs, and Software," Oganisation for Economic Co-Operation and Development, 98 (4).

Bakos, J. Yannis (1997), "Reducing Buyer Search Costs: Implications for Electronic Marketplaces," Management Science, 43 (12), 1676-92.

Beatty, Sharon E. and Scott M. Smith (1987), "External search effort: An investigation across several product categories," Journal of Consumer Research, 14 (1), 83-95.

Bellman, Steven, Gerald L. Lohse, and Eric J. Johnson (1999), "Predictors of Online Buying Behavior," Communications of the ACM, 42, 32-38.

Brown, Jeffrey R. and Austan Goolsbee (2001), "Does the Internet Make Markets More Competitive? Evidence from the Life Insurance Industry.," NBER Working paper.

Brynjolfsson, E. and M. D. Smith (2000), "Frictionless commerce? A comparison of Internet and conventional retailers," Management Science, 46 (4), 563-85.

Clay, Karen, Ramayya Krishnan, and Eric Wolff (2001), "Prices and Price Dispersion on the Web: Evidence from the Online Book Industry," TheJournal of Industrial Economics, 49, 521-39.

Clemons, Eric, Il-Horn Hann, and Loren Hitt (2002), "Price Dispersion and Differentiation in Online Travel: An Empirical Investigation.," Management Science, 48, 534-49.

Diamond, Peter (1987), "Search Theory," in The New Palgraeve: A Dictionary of Economics, John Eatwell and Murray Milgate and Peter K. Newman, Eds. London: Stockton Press.

Johnson, Eric J., S. Bellman, and G. L. Lohse (2002), "Cognitive Lockin and the Power Law of Practice." New York: Department of Marketing, Columbia Business School, Columbia University.

Johnson, Normal L., Samuel Kotz, and Adrienne W. Kemp (1993), Univariate Discrete Distributions (2nd edition ed.). New York: John Wiley \& Sons, Inc. 
Loewenstein, George and Drazen Prelec (1992), "Anomalies in interpersonal choice: Evidence and an interpretation," in Choice over time, George Elster Jon Loewenstein, Ed. New York, NY, USA: Russell Sage Foundation.

Loewenstein, George and Richard H. Thaler (1997), "Intertemporal choice," in Research on judgment and decision making: Currents, connections, and controversies. Cambridge series on judgment and decision making, William Mark Hogarth Robin M. Goldstein, Ed. New York, NY, USA: Cambridge University Press.

McQuivey, James (1999), "Web Buyers Shop Around, Forrester Brief," Forrester Research URL http://www.forrester.com/ER/Research/Brief/0,1317,8670,FF.html.

Moe, Wendy W. and Peter F. Fader (2002), "Dynamic Conversion Behavior at e-Commerce Sites." Philadelphia, PA: Department of Marketing, The Wharton School, University of Pennsylvania.

Moorthy, Sridhar, Brian T. Ratchford, and Debabrata Talukdar (1997), "Consumer information search revisited: Theory and empirical analysis," Journal of Consumer Research, 23 (4), 263-77.

Newman, J. R. (1977), "Consumer External Search: Amount and Determinants," in Consumer and Industrial Buying Behavior, Arch Woodside and Jagdish Sheth and Peter Bennet, Eds. New York: North-Holland.

Putsis, W. P. and N. Srinivasan (1994), "Buying or Just Browsing - the Duration of Purchase Deliberation," Journal of Marketing Research, 31 (3), 393-402.

Scott Morton, Fiona, Florian Zettelmeyer, and Jorge Silva-Risso (2002), "Consumer Information and Price Discrimination: Does the Internet Affect the Pricing of New Cars to Women and Minorities?" UC Berkeley Marketing Working Paper No. 01-2.

Smith, M. D. and E. Brynjolfsson (2001), "Consumer decision-making at an Internet shopbot: Brand still matters," Journal of Industrial Economics, 49 (4), 541-58.

Smith, Michael D, Joseph Bailey, and Eric Brynjolfsson (2000), "Understanding Digital Markets," in Understanding the Digital Economy, Eric Brynjolfsson and Brian Kahin, Eds. Cambridge, MA: MIT Press.

Thaler, Richard H. (1999), "Mental accounting matters," Journal of Behavioral Decision Making, 12 (3), 183-206.

Wilkie, William and Peter Dickson (1985), "Shipping for Appliances--Consumers' Strategies and Peterns of Informatin Search." Cambridge, MA: Marketing Science Institute. 
Table 1. E-Commerce Sites Included in Books, CDs, and Travel Categories (with number of searches per site)

\begin{tabular}{|l|c|l|c|l|c|}
\hline \multicolumn{2}{|c|}{ Books } & \multicolumn{2}{c|}{ CDs } & \multicolumn{2}{c|}{ Air Travel } \\
\hline Amazon & 4721 & MusicBlvd & 1880 & City.Net & 3010 \\
\hline Barnes \& Noble & 2813 & CDNOW & 1655 & Preview Travel & 2095 \\
\hline Books.com & 230 & BestBuy & 498 & Travelocity & 2048 \\
\hline Superlibrary & 229 & CDUniverse & 442 & Expedia & 1988 \\
\hline Borders.com & 127 & Music Central & 271 & American Airlines & 1334 \\
\hline Book Zone & 67 & Tower & 227 & Southwest Airlines & 997 \\
\hline Powells & 61 & Tunes & 189 & Delta Air & 957 \\
\hline AltBookStore & 59 & CDWorld & 107 & ITN & 920 \\
\hline BooksNow & 30 & MassMusic & 94 & Continental & 872 \\
\hline Wordsworth.com & 28 & Newbury & 70 & Travel Web & 817 \\
\hline Acses & 17 & Emusic & 31 & Northwest Airlines & 723 \\
\hline Books-a-Million & 17 & Ktel & 20 & United Airlines & 714 \\
\hline Kingbooks & 4 & CDConnect & 16 & US Airways & 643 \\
\hline & & Music Spot & 14 & Priceline & 512 \\
\hline & & CDEurope & 13 & TWA & 418 \\
\hline & & CDUSA & 11 & Best Fares & 401 \\
\hline & & & & The Trip & 366 \\
\hline & & & & European Travel & 279 \\
\hline & & & & Lowest Fare & 138 \\
\hline & & & & Cheap Tickets & 115 \\
\hline & & & Traska Airlines & 94 \\
\hline & & & 70 \\
\hline
\end{tabular}

NOTE: The numbers in this table represent the actual number of visits performed by the individuals in the data panel and do not represent the total level of activity at the U.S. population level. 
Table 2a. Parameter Estimates for Book Category

\begin{tabular}{|c|c|c|c|c|c|c|c|}
\hline param & mean & std. dev. & $2.50 \%$ & $5.00 \%$ & median & $95.00 \%$ & $97.50 \%$ \\
\hline$K$ & 0.983 & 0.044 & 0.903 & 0.914 & 0.982 & 1.055 & 1.068 \\
\hline$m$ & 4.583 & 0.196 & 4.224 & 4.274 & 4.575 & 4.921 & 4.982 \\
\hline$\beta_{0}$ & -0.176 & 0.088 & -0.323 & -0.314 & -0.176 & -0.034 & -0.001 \\
\hline$\beta_{1}$ & -0.004 & 0.042 & -0.086 & -0.073 & -0.004 & 0.068 & 0.083 \\
\hline$\beta_{2}$ & 0.949 & 0.050 & 0.851 & 0.867 & 0.947 & 1.03 & 1.046 \\
\hline$\phi$ & 4.124 & 0.416 & 3.379 & 3.485 & 4.093 & 4.843 & 4.985 \\
\hline$\sigma_{\beta 0}$ & 3.357 & 0.430 & 2.645 & 2.726 & 3.322 & 4.118 & 4.281 \\
\hline$\sigma_{\beta 1}$ & 3.030 & 0.406 & 2.330 & 2.408 & 3.021 & 3.737 & 3.876 \\
\hline$\sigma_{\beta 2}$ & 4.838 & 0.498 & 3.972 & 4.079 & 4.799 & 5.665 & 5.801 \\
\hline
\end{tabular}

Table 2b. Parameter Estimates for Music Category

\begin{tabular}{|c|c|c|c|c|c|c|c|}
\hline param & mean & std. dev. & $2.50 \%$ & $5.00 \%$ & median & $95.00 \%$ & $97.50 \%$ \\
\hline$k$ & 0.684 & 0.042 & 0.602 & 0.614 & 0.685 & 0.752 & 0.765 \\
\hline$m$ & 4.841 & 0.291 & 4.266 & 4.354 & 4.848 & 5.310 & 5.395 \\
\hline$\beta_{0}$ & 0.868 & 0.148 & 0.563 & 0.629 & 0.860 & 1.084 & 1.103 \\
\hline$\beta_{1}$ & -0.072 & 0.106 & -0.291 & -0.261 & -0.063 & 0.089 & 0.111 \\
\hline$\beta_{2}$ & 0.981 & 0.074 & 0.858 & 0.868 & 0.971 & 1.112 & 1.127 \\
\hline$\phi$ & 3.201 & 0.394 & 2.519 & 2.622 & 3.173 & 3.847 & 3.999 \\
\hline$\sigma_{\beta 0}$ & 2.665 & 0.403 & 1.974 & 2.072 & 2.632 & 3.358 & 3.506 \\
\hline$\sigma_{\beta 1}$ & 2.365 & 0.420 & 1.605 & 1.697 & 2.357 & 3.068 & 3.176 \\
\hline$\sigma_{\beta 2}$ & 4.764 & 0.582 & 3.765 & 3.901 & 4.738 & 5.801 & 5.970 \\
\hline
\end{tabular}

Table 2c. Parameter Estimates for Travel Category

\begin{tabular}{|c|c|c|c|c|c|c|c|}
\hline param & mean & std. dev. & $2.50 \%$ & $5.00 \%$ & median & $95.00 \%$ & $97.50 \%$ \\
\hline$k$ & 1.026 & 0.035 & 0.961 & 0.969 & 1.025 & 1.083 & 1.094 \\
\hline$m$ & 3.404 & 0.121 & 3.189 & 3.219 & 3.399 & 3.612 & 3.649 \\
\hline$\beta_{0}$ & 1.345 & 0.055 & 1.223 & 1.237 & 1.345 & 1.432 & 1.445 \\
\hline$\beta_{1}$ & -0.162 & 0.038 & -0.224 & -0.217 & -0.167 & -0.093 & -0.077 \\
\hline$\beta_{2}$ & 0.720 & 0.024 & 0.664 & 0.675 & 0.722 & 0.753 & 0.758 \\
\hline$\phi$ & 6.486 & 0.521 & 5.415 & 5.533 & 6.524 & 7.331 & 7.545 \\
\hline$\sigma_{\beta 0}$ & 4.632 & 0.491 & 3.832 & 3.919 & 4.614 & 5.504 & 5.644 \\
\hline$\sigma_{\beta 1}$ & 4.836 & 0.504 & 3.903 & 4.033 & 4.802 & 5.715 & 5.891 \\
\hline$\sigma_{\beta 2}$ & 6.644 & 0.567 & 5.498 & 5.635 & 6.697 & 7.523 & 7.654 \\
\hline
\end{tabular}


Figure 1. Average Number of Online Stores Visited During Each Observed Shopping Month

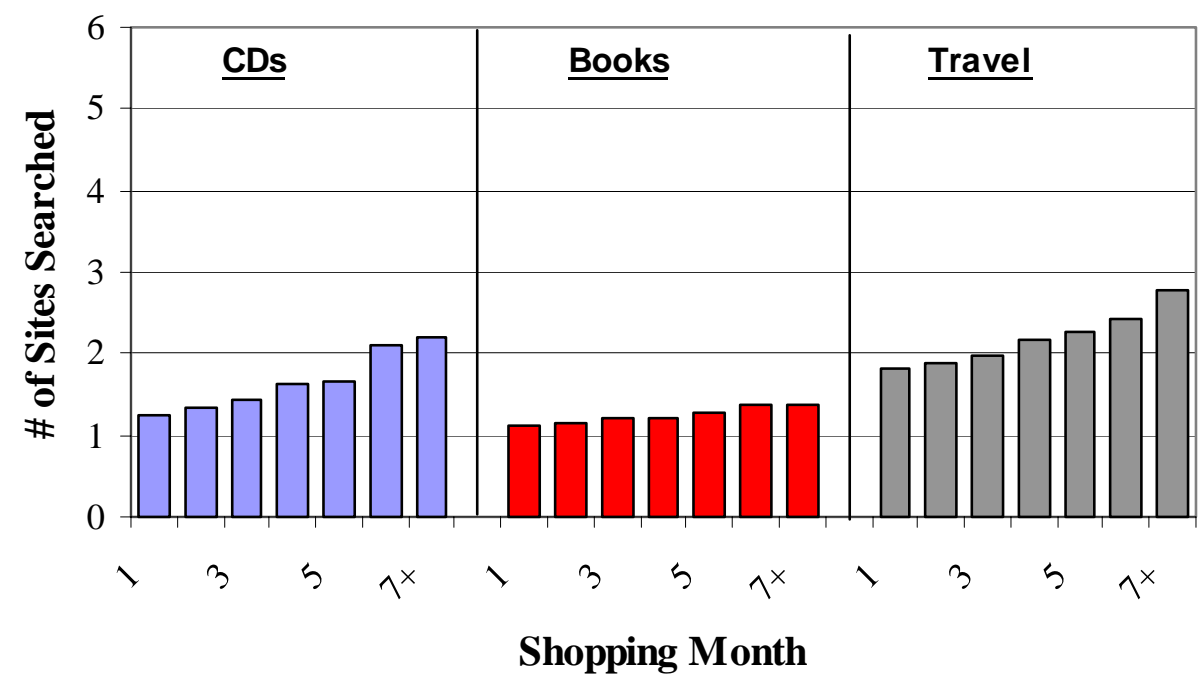

Figure 2. Logarithmic Distribution

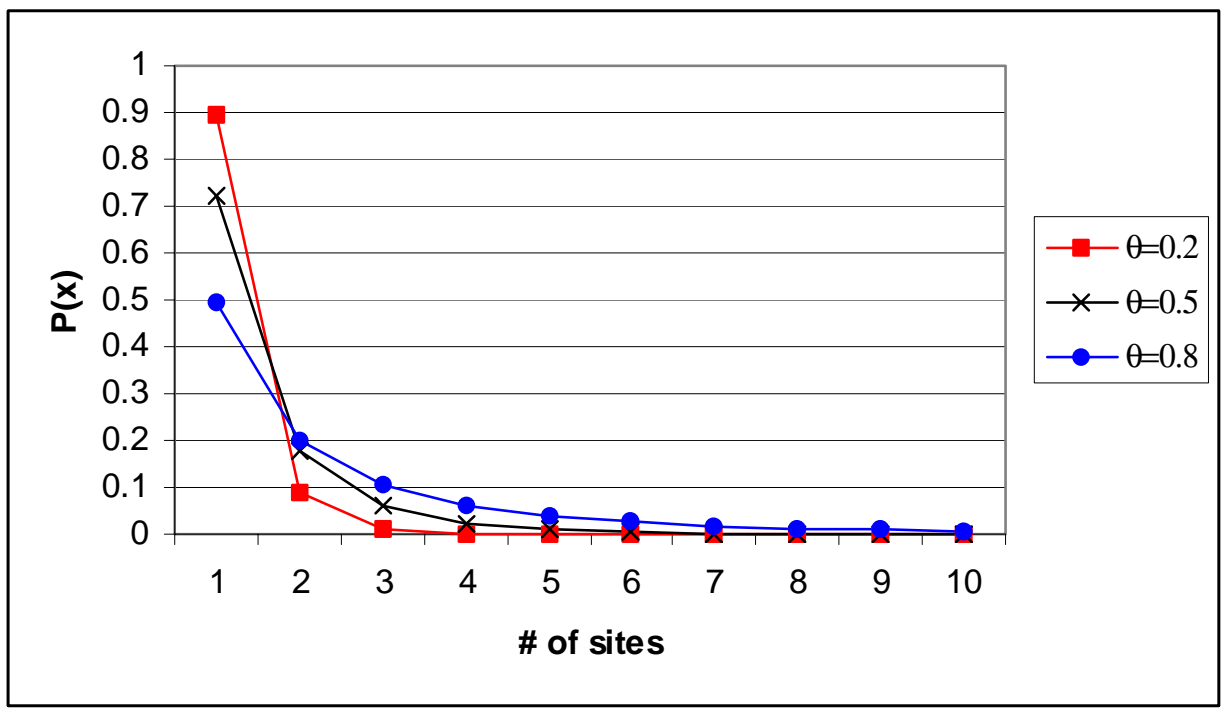




\section{Books}

Music

Travel

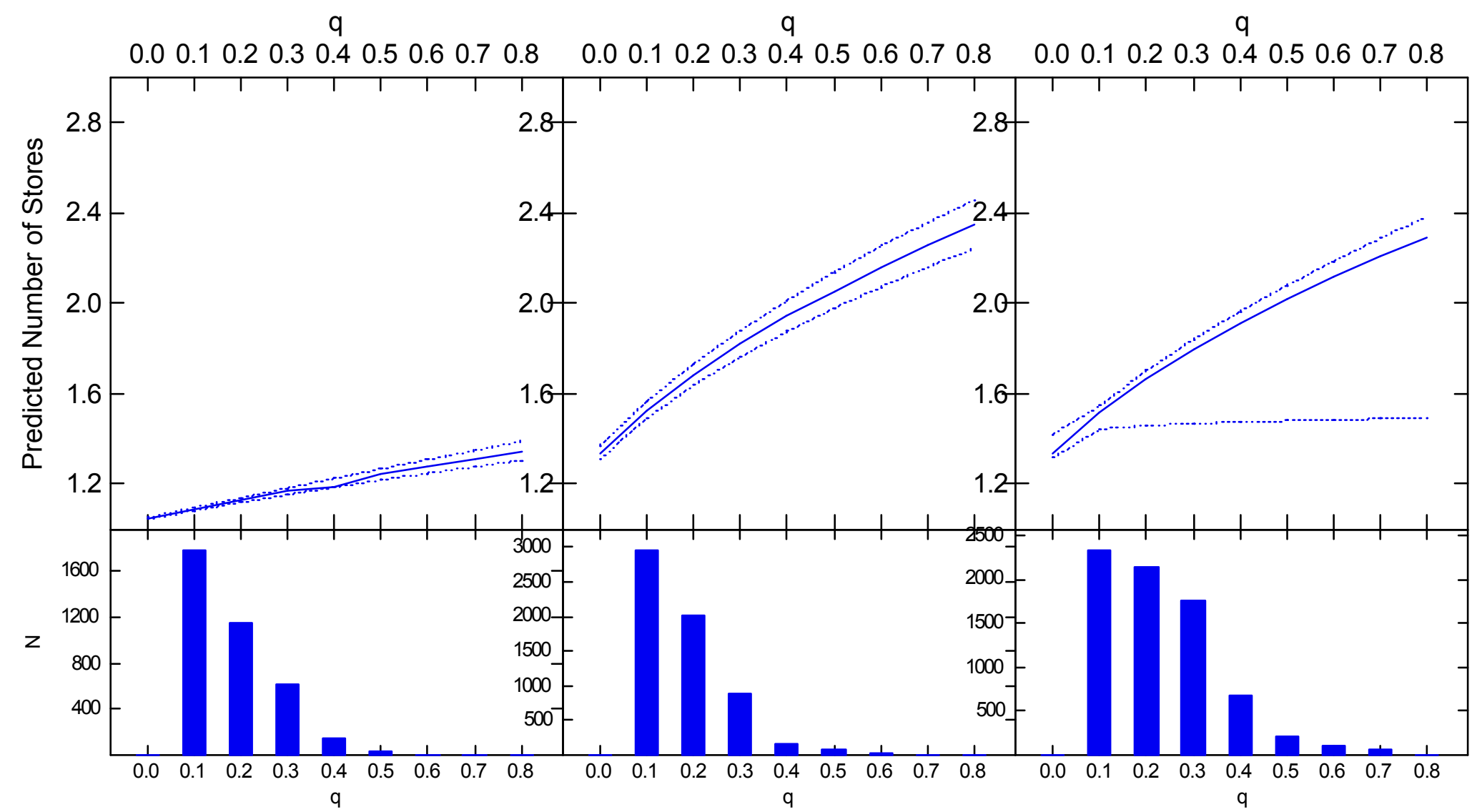

Figure 3. Effect of Search Activity: Estimated Number of Store Visits (Top) and Number of Panelists as a function of Q, propensity to search 